\title{
Aloe vera-Mechanisms of Action, Uses, and Potential Uses in Plastic Surgery and Wound Healing
}

\author{
Waylon M. Zeng1, Anamaria Parus ${ }^{1}$, Connor W. Barnes' ${ }^{2}$, Matthew E. Hiro' ${ }^{1,2,3}$, \\ Martin C. Robson ${ }^{2}$, Wyatt G. Payne ${ }^{1,2,3 *}$ \\ ${ }^{1}$ College of Medicine, University of Central Florida, Orlando, FL, USA \\ ${ }^{2}$ Department of Plastic and Reconstructive Surgery, University of South Florida, Tampa, FL, USA \\ ${ }^{3}$ Institute for Tissue Regeneration, Repair, and Rehabilitation, Surgical Service, Department of Veteran Affairs, Bay Pines VA \\ Health System, Bay Pines, FL, USA \\ Email: *Wyatt.Payne@va.gov
}

How to cite this paper: Zeng, W.M. Barnes, C.W., Hiro, M.E., Parus, A., Robson, M.C. and Payne, W.G. (2020) Aloe vera-Mechanisms of Action, Uses, and Potential Uses in Plastic Surgery and Wound Healing. Surgical Science, 11, 312-328.

https://doi.org/10.4236/ss.2020.1110033

Received: September 2, 2020

Accepted: October 25, 2020

Published: October 28, 2020

Copyright $\odot 2020$ by author(s) and Scientific Research Publishing Inc. This work is licensed under the Creative Commons Attribution International License (CC BY 4.0).

http://creativecommons.org/licenses/by/4.0/

\begin{abstract}
Aloe vera has been used for centuries for medicinal purposes. Clinical and experimental evidence indicates usefulness for skin moisturization, promoting wound healing, thermal skin injury, frostbite, and ischemic skin insults. Aloe vera has anti-inflammatory, vasodilatory, antimicrobial, and proliferative actions, which have been investigated in various experimental models and in various in vitro studies. This extensive literature review of the properties and actions of Aloe vera finds substantial evidence for the reported and also likely clinical usefulness for Aloe vera in Plastic Surgery and in wound care and wound healing. Though further clinical investigation is warranted, Aloe vera use may likely be indicated in situations where its effects could positively influence outcomes, such as wound healing, flap vascularity, and inflammatory skin pathologies.
\end{abstract}

\section{Keywords}

Aloe vera, Wound Healing, Anti-Inflammatory, Prostaglandin, Anti-Microbial, Anti-Oxidant, Angiogenesis

\section{Introduction}

Aloe vera is a succulent tropical plant native to the Arabian Peninsula. Early documented usage of the plant dates back to ancient Greece and Egypt, where it was used to alleviate sunburns and as skin beauty care [1]. Aloe vera was utilized regularly to aid in wound healing during times of war and exploration, from 
Alexander the Great's conquests to Christopher Columbus's journeys to the New World [2]. While Aloe vera has been regularly used in alternative and complementary medicine, it has not yet been widely incorporated into the clinical practice of western medicine.

The skin is the largest organ in the human body and serves as a protective barrier from the outside environment. It functions in homeostasis and thermoregulation and is the first line of defense against foreign pathogens. Skin disease and injury may be the result of many pathophysiologies. In those which result in local tissue ischemia and cell death, the microcirculation in dermal tissue is affected. In injuries due to heat, cold, chemicals, electricity, crush, friction, radiation, or other wound etiologies, ischemic microvascular changes occur in nonreversible damage zones of dermal tissue, resulting in cell death. However, reversible and relatively ischemic areas are potentially salvageable [3] [4] [5]. Thus, an agent that would inhibit ischemia, microbes, and inflammation would be of positive value to support and augment wound healing.

The mucilaginous tissue in the Aloe vera leaf contains phytochemicals, and its anti-oxidative, anti-inflammatory, anti-microbial, and proliferative properties have been shown to promote wound healing in both animal and human models [6] [7] [8] [9]. Enhancing these properties can help augment blood supply and tip the scale of relative ischemia to adequate perfusion, thereby salvaging reversible ischemic skin injury.

This review describes and identifies the effects and mechanisms that Aloe vera has on skin care and wound healing. We then propose uses and the potential utility of Aloe vera in the field of plastic surgery as it pertains to wound healing.

\section{Review}

The myriad of compounds that make up the composition of Aloe vera gel has been shown to have positive therapeutic properties in skin wound healing as well as other acute and chronic disease processes [10]. Table 1 lists the constituents that have been isolated from Aloe vera. We discuss Aloe vera's anti-inflammatory and vasodilatory, anti-microbial, anti-oxidant, and proliferative effects on skin healing. We also propose clinical uses based on the available data of its mechanisms of action.

\subsection{Anti-Inflammatory and Vasodilatory Effects}

Prostaglandins and thromboxanes are eicosanoid compounds formed from arachidonic acid. They serve as signaling molecules that are present in most tissues and organs, and they are necessary to orchestrate complex inflammatory reactions [11] [12] [13]. Eicosanoids are synthesized using two isoforms of cyclooxygenases. Knockout of cyclooxygenase (COX) genes in mice has been shown to impair inflammatory responses [14]. Clinically, nonsteroidal anti-inflammatory drugs (NSAIDs) and corticosteroids are used to reduce the inflammatory response by targeting the arachidonic pathway that produces these molecules. 
Table 1. Known compounds isolated from Aloe vera Leaf [10] [61].

\begin{tabular}{|c|c|}
\hline Anthraquinones & Inorganic compounds \\
\hline Aloe-emodin & Calcium \\
\hline Aloetic acid & Chlorin \\
\hline Aloin $\mathrm{A}$ and $\mathrm{B}$ & Chromium \\
\hline Anthranol & Copper \\
\hline Barbaloin & Iron \\
\hline Chrysophanic acid & Magnesium \\
\hline Emodin & Manganese \\
\hline Emolin & Potassium sorbate \\
\hline Ester of cinnamic acid & Sodium \\
\hline Isobarbaloin & Zinc \\
\hline \multicolumn{2}{|l|}{ Resistannol } \\
\hline & Enzymes \\
\hline Saccharides & Alkaline phosphatase \\
\hline Aldopentose & Amylase \\
\hline Cellulose & Carboxypeptidase \\
\hline Glucose & Catalase \\
\hline L-rhamnose & Cyclooxygenase \\
\hline \multirow[t]{2}{*}{ Mannose } & Glutathione peroxidase \\
\hline & Lipase \\
\hline Vitamins & Oxidase \\
\hline B1 Thiamine & Phosphoenolpyruvate carboxylase \\
\hline B2 Riboflavin & Superoxide dismutase \\
\hline \multicolumn{2}{|l|}{ B6 Pyridoxine } \\
\hline B9 Folic acid & Essential amino acids \\
\hline C Ascorbic acid & Isoleucine \\
\hline Choline & Leucine \\
\hline E $\alpha$-tocopherol & Lysine \\
\hline \multirow[t]{2}{*}{$\beta$-carotene } & Methionine \\
\hline & Phenylalanine \\
\hline Miscellaneous & Threonine \\
\hline Arachidonic acid & Valine \\
\hline \multicolumn{2}{|l|}{$\beta$-sitosterol } \\
\hline Campesterol & Nonessential amino acids \\
\hline Cholesterol & Alanine \\
\hline Gibberellin & Arginine \\
\hline Lignins & Aspartic acid \\
\hline
\end{tabular}




\section{Continued}

\begin{tabular}{|c|c|}
\hline Salicylic acid & Glutamic acid \\
\hline Triglycerides & Glycine \\
\hline Triterpenoid & Histidine \\
\hline Uric acid & Hydroxyproline \\
\hline \multirow[t]{2}{*}{$\gamma$-linolenic acid } & Proline \\
\hline & Tyrosine \\
\hline \multicolumn{2}{|l|}{ Carbohydrates } \\
\hline Acemannan & Chromones \\
\hline Acetylated glucomannan & 8- $C$-glucosyl-(2'-O-cinnamoyl)-7- $O$-methylaloediol A \\
\hline Acetylated mannan & 8- $C$-glucosyl- $(S)$-aloesol \\
\hline Arabinogalactan & 8- $\mathrm{C}$-glucosyl-7- $O$-methyl-aloediol \\
\hline Cellulose & 8- $C$-glucosyl-7- $O$-methyl-( $S$ )-aloesol \\
\hline Galactan & 8- $C$-glucosyl-noreugenin \\
\hline Galactogalacturan & Aloesin \\
\hline Galactoglucoarabinomannan & Isoaloeresin D \\
\hline Glucogalactomannan & Isorabaichromone \\
\hline Peptic substance & Neoaloesin A \\
\hline \multicolumn{2}{|l|}{ Pure mannan } \\
\hline \multirow[t]{3}{*}{ Xylan } & Proteins \\
\hline & Lectins \\
\hline & Lectin-like substance \\
\hline
\end{tabular}

There is a balance between the vasodilatory actions of certain prostaglandins and the vasoconstricting actions of thromboxanes. Found at the endothelial border, prostaglandin $\mathrm{E}_{1}\left(\mathrm{PGE}_{1}\right)$ and prostaglandin $\mathrm{I}_{2}\left(\mathrm{PGI}_{2}\right)$ are vasodilators that counteract the vasoconstricting effects of thromboxane $B_{2}\left(T_{x} B_{2}\right)$ and prostaglandin $\mathrm{F}_{2 \alpha}\left(\mathrm{PGF}_{2 \alpha}\right)$ [15] [16]. Robson et al. demonstrated histologic imbalances of the two forces in burned tissues [4]. As perfusion is paramount for the viability of the burn wound zone of stasis, reducing vasoconstricting prostaglandins and increasing vasodilatory endogenous prostaglandin mediators reduce areas of dermal ischemia. Exogenous prostaglandins (specifically $\mathrm{PGI}_{2}$ ) delivered intravenously to an experimental axial skin flap model showed significantly greater flap survival compared to controls [17]. Inhibition of thromboxane (specifically $\mathrm{T}_{\mathrm{x}} \mathrm{B}_{2}$ ) has been shown to support perfusion of the dermal and subdermal plexuses [3] [18]. When used in combination, synergistic effects of inhibiting thromboxane and injecting prostaglandin $I_{2}$ resulted in an even higher percentage of skin flap survival by promoting increased perfusion to ischemic flap tissue compared to control [19]. Subsequently, use of selective thromboxane inhibitors such as thromboxane synthetase inhibitors and cyclooxygenase inhibitors have been shown to increase wound perfusion [18]. 
Cera et al. reported Aloe vera's effects of inhibiting $\mathrm{T}_{\mathrm{x}} \mathrm{B}_{2}$ in burn injuries [20]. Aloe vera cream (Dermaide Aloe ${ }^{\circledR}$ ) and aspirin have been shown to prevent progression of frostbite injuries following rapid rewarming [21]. DelBeccaro et al. and Heggers et al. both attributed increased tissue survivability in frostbite, electrical, intra-arterial drug, and thermal injuries to the vasodilatory effects of Aloe vera and other anti-thromboxane agents such as methimazole and imidazole [18] [22]. Use of Aloe vera alone and when combined with another specific anti-thromboxane agent (methimazole) were shown to have the greatest effects of tissue survival, wound healing, and decreased morbidity in dermal injury with associated ischemia [22].

Extracts of the phytochemical constituents present in Aloe vera, have demonstrated anti-inflammatory and vasodilatory activity through COX inhibition [23]. Salicylic acid, a known COX inhibitor, is present in large quantity in fresh Aloe vera [24]. Anthraquinones are aromatic organic compounds found in numerous plants. Emodin and emolin, anthraquinone derivatives found in Aloe, act as competitive inhibitors of thromboxane synthetase and have significant anti-inflammatory properties [25].

Other Aloe vera compounds have been shown to modulate the inflammatory response. Aloesin appears to affect migration of both fibroblasts and leukocytes [26]. In early phases of wound healing, Aloesin promotes leukocyte extravasation and cytokine and growth factor release. Aloesin is thought to act on leukocyte migration via phosphorylation of $\mathrm{Cdc} 42$ and Rac1, signaling proteins that coordinate and regulate actin dynamics and cell polarization [27]. The inflammatory markers TNF- $\alpha$, IL- $1 \beta$, IL- 6 , and TGF- $\beta 1$ mediate leukocyte signaling, migration, and phagocytosis, and are significantly increased in the presence of aloesin. Another Aloe pro-inflammatory compound is acemannan. Acemannan activates macrophages and enhances bactericidal activity [28] [29]. Additionally, Aloe extracts have been shown to decrease inflammatory markers and affect DNA repair capacity [30] [31]. Wahedi et al. demonstrated significant decreases in macrophage and neutrophil activity in later phases of inflammation with Aloesin administration [26]. Use of Aloe on experimental burn wounds demonstrated a significant decrease in TNF- $\alpha$ and IL- 6 levels and reduction in leukocyte adhesion on postcapillary venules [31]. NAE- $8^{\circledR}$, an Aloe vera-based extract, has been shown to decrease levels of TNF- $\alpha$ and IL-1 $\beta$ [30].

\subsection{Anti-Microbial Effects}

Because injury site is prone to infection, topical treatment with antimicrobial agents is frequently utilized in burn wound treatment. Silvadene ${ }^{\circledR}$ cream contains $1 \%$ micronized silver sulfadiazine. It is an antimicrobial agent commonly used for partial and full thickness burns. However, silver sulfadiazine can negatively affect wound healing time [32]. Heggers et al. demonstrated that the wound retardant effect of silver sulfadiazine could be reversed with the addition of Aloe gel [33]. This is likely due to anthraquinone derivatives emodin, 
Aloe-emodin, aloin, and chrysophanic acid, which have both antimicrobial and anti-inflammatory activity [20] (Table 2).

Anthraquinones have been shown to exhibit antimicrobial properties by altering solute transport through membranes, cell walls, and fatty acid elongation [10] [34]. Reports vary, but some studies demonstrate up to 18 species of microorganisms inhibited by Aloe preparations [6]. Aloe vera was able to inhibit

Table 2. Aloe vera compounds listed by mechanisms of action [7] [8] [20] [24]-[30] [45] [46] [47] [48] [49].

Immunomodulatory compounds

Acemannan

Aloe-emodin

Aloesin

Anthraquinones

Arabinogalactan

Arachionic acid

Cyclooxygenase

Emodin

Emolin

Glucomannan

Lectin-like substance

Neoaloesin A

Salicylic acid

Anti-microbial compounds

Aloe-emodin

Aloin

Chrysophanic acid

Emodin

Anti-oxidant compounds

C Ascorbic acid

Catalase

Chromones

E $\alpha$-tocopherol

Glucomannan

Glutathione peroxidase

Superoxide dismutase

Proliferative compounds

Aloesin

F3 Fraction

$\beta$-sitosterol 
growth at extract concentrations as low as $60 \%$ of bacterial strains, such as $\mathrm{Ci}$ trobacter sp., Serratia marcescens, Enterobacter cloacae, Klebsiella pneumonia, Pseudomonas aeruginosa, $S$. aureus, $S$. pyogenes, and $S$. agalactiae. Other species such as E. coli, Enterococcus, and Candida albicans were more resistant, requiring higher concentrations for significant inhibition; however, all bacterial species responded to treatment [35].

\subsection{Anti-0xidant Effects}

Reactive oxygen species (ROS) are naturally formed as a byproduct of cellular oxidative phosphorylation in cytochrome oxidation, phagocytosis, and the inflammatory process. Normally, the body maintains a balance of anti-oxidant enzymes, mainly superoxide dismutase and glutathione synthetase. In the presence of increased oxidants (tissue injury), the balance is shifted, which may cause local or systemic healing and homeostatic dysfunction [36].

Formation of reactive oxygen species in the presence of significant traumatic or metabolic injury is of concern due to the potential for sepsis and organ failure [36] [37]. As a tissue metabolite, the reactive species causes local vascular changes to redirect tissue perfusion. In the presence of pathologic stimulus, redirection of perfusion can be significant enough to cause ischemia to distant organs. Additional insult produces more ROS to be released systemically, which may lead to worsening distant ischemia, sepsis, and tissue inflammation [36] [38].

The role of antioxidants is important as a complement to primary intervention to prevent systemic effects of oxidative species. Enhancing native enzymatic defenses against ROS have been shown to reduce tissue ischemia and oxidative injury [39]. A dose-dependent anti-oxidant effect is observed in Aloe vera due to its glutathione peroxidase activity, superoxide dismutase enzymes, and phenolic anti-oxidants [8] [10]. NAE-8 ${ }^{\circledR}$ similarly promotes a reduction of lipid peroxidation and supports the maintenance of cellular integrity. Akgun et al. demonstrated reduction in elevated malondialdehyde, glutathione, and myeloperoxidase levels in burns with this extract, indicating decreased inflammatory response secondary to Aloe's potent antioxidant effects [30].

\subsection{Proliferative Wound Healing Effects}

Aloe vera extract influences initial short-term inflammation promoting neutrophil infiltration and cytokine release. Activated leukocytes, macrophages, and fibroblasts release cytokines and growth factors to initiate angiogenesis and wound healing. While tissue inflammation is eventually reduced in the presence of Aloe extracts, the presence of growth factors is sustained. Transforming growth factor-Beta 1 (TGF- $\beta 1$ ) is a major growth factor in wound healing [40]. Some functions include: increasing migration and mitosis of fibroblasts and keratinocytes, angiogenesis, formation of extracellular matrix, and differentiation of cells [41] [42]. Wahedi et al. described aloesin's positive effects on upregulat- 
ing SMAD and MAPK signaling pathways, which are critical for collagen development and angiogenesis [43]. By upregulating these signaling pathways, Aloe vera can stimulate increased rates of re-epithelialization and angiogenesis by increasing TGF- $\beta$ activity [44].

Other growth factors affected by Aloe extracts include vascular endothelial growth factor (VEGF) and basic fibroblast growth factor (bFGF). Moon et al. attributed increased expression of VEGF with $\beta$-sitosterol, a compound found in Aloe vera [45]. $\beta$-sitosterol is known to enhance expression of other angiogenic proteins, such as van Willebrand Factor (vWF), VEGF receptor (Flk-1), and matrix laminin [46]. With dichloromethane extraction of Aloe vera gel, Lee et al. isolated an active fraction (F3) which appears to increase proliferation of endothelial cells and increases extracellular matrix proteolytic enzymes for vascular remodeling [47] [48]. Aloe has also been shown to increase bFGF and TGF- $\beta$ levels at wound sites [49].

The Rho family GTPases are important in regulating actin cytoskeleton and cellular migration. Specifically, Rho, Rac, and Cdc42 have been shown to have essential roles in normal wound closure and healing [50]. Wounds treated with aloesin demonstrated significant increases in keratinocyte migration rate and upregulated expression of activated Rac1 and Cdc42 in a dose-dependent manner of aloesin. This resulted in increased rates of wound closure and dermal regeneration compared to untreated mice models [26]. NAE- $8^{\circledR}$ treatment showed similar effects on migration of fibroblasts, which act synergistically with keratinocytes; their proliferation increased matrix protein, fibronectin, proteoglycan, hyaluronan, and collagen production [30].

Wahedi et al. demonstrated a qualitative and quantitative improvement in collagen production in wounds treated with aloesin. The treated group exhibited increased amounts of collagen deposition after days 5 and 10, and improvement in the organization of collagen complexes, compared to control groups [26]. Heggers et al. found that lectins from Aloe vera increased collagen activity, which increased wound contraction and breaking strength [22]. Collagen synthesis by fibroblasts also depends on the presence of oxygen, which is further augmented by Aloe vera due to its vasodilatory effects [7] [51].

Aloe vera decreases wound healing time in skin wound and injuries due likely to the interplay of the above processes. An efficacy study on wound healing times indicated a summary weighted mean difference in healing time that was 8.79 days shorter in the Aloe vera group [52]. Results were most improved in first and second degree burns, where perfusion is salvageable. Additional experimental models have demonstrated modulation of inflammation, increased wound contraction and epithelialization, decreased and better organized scar, that ultimately results in a greater maximum wound strength and elasticity, when wounds were treated with Aloe vera [53]. Aloe vera and its extract isolates are associated with decreased pain, shorter healing time, improved wound contracture, and increased breaking tensile strength [22] [52] [53]. Proliferative 
compounds found in Aloe vera are listed in Table 2.

\section{Discussion}

\section{Aloe vera Uses and Potential Uses}

Due to the relatively limited side effect profile from the use of Aloe vera compared to systemic drugs such as steroids or COX inhibitors, Aloe vera topical cream is a favorable complement for skin injuries. Steroids and COX inhibitors reduce the initial phase of inflammation and proliferation. Aloe extracts have been able to modulate inflammatory response to best promote healing [28] [29] [30]. Use of some topical antimicrobials can negatively impact wound healing time due to inhibitory effects on keratinocytes and fibroblasts. When used in conjunction with these treatments, Aloe vera extracts can negate some of their adverse effects [33] [54].

Some studies have shown a lack of significant results with Aloe vera application versus control groups assessing wound healing [55] [56]. Cuttle et al. demonstrated little evidence in decreasing microflora concentrations or improving scar maturation of burn wounds [57]. Topman et al. determined no significance in fibroblast migration kinematics, while Coelho et al. observed no difference in wound repair between the sample groups [55] [56]. This is likely due to a common issue with many natural product medications: a lack of standardization of extract concentrations. It is possible that some of these studies used Aloe extracts with insufficient concentrations of active compounds that have the known anti-inflammatory and proliferative effects. The study performed by Cuttle et al. also had the Aloe vera mixed further with other alternative therapies such as saliva and tea tree oil impregnated dressing [57].

Because the concentration of active ingredients in plants may vary depending on age, growing environment, and extraction methods, it is beneficial to extract the ingredients as a concentrate before application [52] [58]. This is seen with the use of Dermaide Aloe ${ }^{\circledR}$, a commercially purified extract, which when compared to other crude extracts, was shown to have higher antimicrobial effects with lower doses of the product [59]. Active ingredients in Aloe extracts also deteriorate with time [52] [60]. Auto-degradation of the mucilage polysaccharides can be retarded with the addition of microalgae polysaccharides [60].

What also differentiates Aloe vera products and its derivatives from other topical medications is low side effect profile and a lack of serious adverse reactions. Adverse effects noted by patients include transient burning sensation after application, skin hyperpigmentation, contact dermatitis, mild itching, and transient leukocytosis [6] [52] [61]. Some of the skin irritation such as the itching and burning may be associated with wound inflammation itself. The transient leukocytosis is likely due to the immunostimulating compounds, such as acemannan. Reynolds et al. noted some cytotoxic effects found in several other studies, but these were more associated with chemical solvents used during commercial processing [6]. 
The use of Aloe vera is not limited to high temperature thermal injuries. Much of the tissue damage caused by frostbite is due to partial thawing and refreezing-or recurring frostbite-which is the result of progressive thrombosis of microvasculature [62]. The frostbite pathophysiology of progressive tissue ischemia is not unlike the mechanisms of other burn wounds. Evaluation of frostbite blister fluid revealed similar enzymes and inflammatory mediators [12] [62]. Similar to thermal burn wounds, there is a balance between vasodilatory prostaglandins and vasoconstricting thromboxane present with frostbite injuries. When comparing Aloe vera cream used in controlled rabbit frostbite wound models, tissue survival was up to four times greater when utilized as a cream [63]. Aloe vera is not effective in all types of thermal injuries. Liquid propane freeze injuries damage tissue differently than thermal burn wounds. Skin was unsalvageable and use of Dermaide Aloe ${ }^{\circledR}$ did not significantly improve outcomes [64].

A randomized controlled trial on split-thickness skin graft (STSG) donor site wound healing time was performed by comparing Aloe vera gel with a medical lubricant [65]. Similar in pathology to partial thickness burn injury, STSG donor site wounds require regular moist dressing changes as skin re-epithelialization occurs. The authors found statistical significance in the times to complete epithelialization, which demonstrated Aloe vera's efficacy in wound healing [65]. There is some evidence for potential Aloe vera use in the treatment of radiation-induced dermatitis [66]. However, this evidence seems inconclusive, as several other studies indicate damage from radiation therapy did not improve significantly with Aloe vera gel compared to control group [67] [68]. Given oral lyophilized Aloe powder dissolved in purified water, rat models with radiation exposure had significantly accelerated wound contraction [69]. Aloe-treated rats were shown to have increased TGF- $\beta 1$ and bFGF activity with significantly less inflammatory cells, more fibroblasts and blood vessels 15 days post-wounding when compared to radiation exposure only rats [69].

Aloe vera's vasodilatory and angiogenic properties along with its other proliferative anti-inflammatory effects may have a role in microcirculatory disease and injury. Aloe vera has already been shown to decrease leukocyte adhesion and maintain increased arteriolar diameter and permeability in microcirculation of burn models [70]. Maintaining proper perfusion to skin flaps is a common challenge in plastic surgery, and microvascular thrombosis and endothelial cell injury have been implicated in ischemia [71]. Thrombogenic factors are increased at the anastomosis sites in the animal models with skin flaps. It has been shown that antithrombotic treatment modalities have an effect on thrombus formation and preventing ischemia-related injury [71] [72]; these modalities were further demonstrated to increase skin flap survival and decrease necrosis [73]. The antithrombotic effects of Aloe vera can be a similarly effective means of maintaining perfusion in thermal injuries [3] [18] [21]. Further studies may show a possible use of Aloe vera topical agents in maintaining skin flap perfu- 
sion and viability.

The microvasculature is a location affected by certain systemic and autoimmune diseases. In particular, cutaneous involvement of systemic diseases such as scleroderma (systemic sclerosis, SSc) and systemic lupus erythematosus (SLE) will often begin with microvascular manifestations. Conditions such as Raynaud's phenomenon, livedo reticularis, and acrocyanosis are common in these diseases due to vasospasm and inhibition of vessel dilation upon cold exposure [74] [75] [76]. The vasospasm and lack of perfusion for long periods may eventually lead to digital ulcers, gangrene, and cutaneous infarction [5].

The pathophysiology of these disease processes is similar. As autoimmune disease processes, SSc and SLE produce autoantibodies against endothelial cells, causing vasculopathy, digital infarcts, thrombosis, and vasoconstriction [5] [77] [78] [79]. Endothelial damage and autoantibodies also lead to leukocyte recruitment and extravasation through the upregulation of adhesion molecules (E-selectin, ICAM-1, VCAM-1) and cytokines [79]. With elevated oxidized-LDL, scleroderma can induce a pro-inflammatory response and generation of free radicals, along with a pro-coagulative state from increased thrombogenic factors, to form atherosclerotic plaques [80] [81]. Vasospasm may occur in SSc, as damaged cells have decreased expression of nitric oxide (NO) and increased endothelin-1 (ET), leading to a vasoconstrictive, ischemic state.

Aloe vera may have efficacy in managing skin manifestations of these disease processes. Topical application of nitroglycerin paste has been shown to reduce digital ulcers and ischemia through localized venodilation and smooth muscle relaxation [82]. When comparing nitroglycerin with Aloe vera in wound healing, topical Aloe compound (Dermaide Aloe ${ }^{\circledR}$ ) appeared to promote wound healing faster than nitroglycerin while also having less systemic adverse effects [83] [84]. The progression of these diseases is related to the vasculopathy that occurs through endothelial damage, coagulation, vasospasm, inflammation, and dysregulated angiogenesis. It is possible that Aloe vera may be effective for treatment of cutaneous manifestations of systemic sclerosis and systemic lupus erythematosus, acting upon multiple patho-mechanisms with the expectation of positive results.

\section{Conclusion}

Aloe vera's complex chemistry has been shown to act directly on wound and pathological sites or synergistically with other medications. Its properties as an anti-inflammatory, anti-microbial, anti-oxidative, antithrombotic, vasodilatory, and tissue proliferative agent have been shown to significantly decrease skin wound healing time and improve wound contracture and strength. Aloe is most efficacious with superficial and partial thickness burn wounds. There is some evidence that different preparations of Aloe can have many other therapeutic uses in management of plastic surgery and wound healing. Potential applications include use for frostbite, skin flap and graft surgery, cutaneous manifestations of 
systemic autoimmune diseases, and skin ischemia.

\section{Disclaimer}

The contents of this work do not represent the views of the Department of Veterans Affairs or the United States Government.

\section{Conflicts of Interest}

The authors declare no conflicts of interest regarding the publication of this paper.

\section{References}

[1] Long, V. (2016) Aloe vera in Dermatology-The Plant of Immortality. JAMA Dermatology, 152, 1354-1364. https://doi.org/10.1001/jamadermatol.2016.0077

[2] Barcroft, A. (1996) Aloe vera: Nature's Legendary Healer. Souvenir Press, London.

[3] Robson, M.C., Del Beccaro, E.J. and Heggers, J.P. (1979) The Effect of Prostaglandins on the Dermal Microcirculation after Burning, and the Inhibition of the Effect by Specific Pharmacological Agents. Plastic and Reconstructive Surgery, 63, 781-787. https://doi.org/10.1097/00006534-197963060-00003

[4] Heggers, J.P., Loy, G.L., Robson, M.C. and Del Beccaro, E.J. (1980) Histological Demonstration of Prostaglandins and Thromboxanes in Burned Tissue. Journal of Surgical Research, 28, 110-117. https://doi.org/10.1016/0022-4804(80)90153-5

[5] Saygin, D., Highland, K. and Tonelli, A.R. (2018) Microvascular Involvement in Systemic Sclerosis and Systemic Lupus Erythematosus. Microcirculation, 26, e12440. https://doi.org/10.1111/micc.12440

[6] Reynolds, T. and Dweck, A.C. (1999) Aloe vera Leaf Gel: A Review Update. Journal of Ethnopharmacology, 68, 3-37. https://doi.org/10.1016/S0378-8741(99)00085-9

[7] Davis, R.H., Leitner, M.G., Russo, J.M. and Byrne, M.E. (1989) Wound Healing. Oral and Topical Activity of Aloe vera. Journal of the American Podiatric Medical Association, 79, 559-562. https://doi.org/10.7547/87507315-79-11-559

[8] Hashemi, S.A., Madani, S.A. and Abediankenari, S. (2015) The Review on Properties of Aloe vera in Healing of Cutaneous Wounds. BioMed Research International, 2015, Article ID: 714216. https://doi.org/10.1155/2015/714216

[9] Heggers, J.P., Robson, M.C. and Doran, E.T. (1969) Quantitative Assessment of Bacterial Contamination of Open Wounds by a Slide Technique. Transactions of the Royal Society of Tropical Medicine and Hygiene, 63, 532-534. https://doi.org/10.1016/0035-9203(69)90043-1

[10] Hamman, J.H. (2008) Composition and Applications of Aloe vera Leaf Gel. Molecules, 13, 1599-1616. https://doi.org/10.3390/molecules13081599

[11] Ricciotti, E. and Fitz Gerald, G.A. (2011) Prostaglandins and Inflammation. Arteriosclerosis, Thrombosis, and Vascular Biology, 31, 986-1000. https://doi.org/10.1161/ATVBAHA.110.207449

[12] Robson, M.C. and Heggers, J.P. (1981) Evaluation of Hand Frostbite Blister Fluid as a Clue to Pathogenesis. Journal of Hand Surgery, 6, 43-47. https://doi.org/10.1016/S0363-5023(81)80010-X

[13] Donski, P.K., Franklin, J.D., Hurley, J.V. and O’Brien, B.M. (1980) The Effects of Cooling on Experimental Free Flap Survival. British Journal of Plastic Surgery, 33, 353-360. https://doi.org/10.1016/S0007-1226(80)90082-X 
[14] Langenbach, R., Morham, S.G., Tiano, H.F., et al. (1995) Prostaglandin Synthase 1 Gene Disruption in Mice Reduces Arachidonic Acid-Induced Inflammation and Indomethacin-Induced Gastric Ulceration. Cell, 83, 483-492. https://doi.org/10.1016/0092-8674(95)90126-4

[15] Talmage, J.R., London, M.D., Goluch, L., Heggers, J.P. and Robson, M.C. (1980) Antiprostaglandins and Antithromboxanes for Treatment of Frostbite. Surgical Forum, 31, 557-559.

[16] Zachary, L.S., Heggers, J.P., Robson, M.C. and Leach, A. (1982) Effects of Exogenous Prostacyclin on Flap Survival. Surgical Forum, 33, 588-589.

[17] Reus, W.F., Murphy, R.C., Heggers, J.P., Robson, M.C. and McCauley, R.L. (1984) Effect of Intraarterial Prostacyclin on Survival of Skin Flaps in the Pig: Biphasic Response. Annals of Plastic Surgery, 13, 29-33. https://doi.org/10.1097/00000637-198407000-00006

[18] DelBeccaro, E.J., Robson, M.C., Heggers, J.P. and Swaminathan, R. (1980) The Use of Specific Thromboxane Inhibitors to Preserve the Dermal Microcirculation after Burning. Surgery, 87, 137-141.

[19] Zachary, L.S., Heggers, J.P., Robson, M.C. and Murphy, R.C. (1986) Combined Prostacyclin and Thromboxane Synthetase Inhibitor UK 38485 in Flap Survival. Annals of Plastic Surgery, 17, 112-115. https://doi.org/10.1097/00000637-198608000-00004

[20] Cera, C.M., Heggers, J.P., Robson, M.C. and Hagstrom, W.J. (1980) The Therapeutic Efficacy of Aloe vera Cream (Dermaide Aloe) in Thermal Injuries: Two Case Reports. Journal of the American Animal Hospital Association, 16, 768-772.

[21] McCauley, R.L., Hing, D.N., Robson, M.C. and Heggers, J.P. (1983) Frostbite Injuries: A Rational Approach Based on the Pathophysiology. The Journal of Trauma, 23, 143-147. https://doi.org/10.1097/00005373-198302000-00013

[22] Heggers, J.P., Kucukcelebi, A., Listengarten, D., et al. (1996) Beneficial Effect of Aloe on Wound Healing in an Excisional Wound Model. The Journal of Alternative and Complementary Medicine, 2, 271-277. https://doi.org/10.1089/acm.1996.2.271

[23] Vazquez, B., Avila, G., Segura, D. and Escalante, B. (1996) Antiinflammatory Activity of Extracts from Aloe vera Gel. Journal of Ethnopharmacology, 55, 69-75. https://doi.org/10.1016/S0378-8741(96)01476-6

[24] Zachary, L.S., Smith, D.J., Heggers, J.P., et al. (1987) The Role of Thromboxane in Experimental Inadvertent Intra-Arterial Drug Injections. Journal of Hand Surgery (American Volume), 12, 240-245. https://doi.org/10.1016/S0363-5023(87)80279-4

[25] Penneys, N.S. (1982) Inhibition of Arachidonic Acid Oxidation in Vitro by Vehicle Components. Acta Dermato- Venereologica, 62, 59-61.

[26] Wahedi, H.M., Jeong, M., Chae, J.K., Do, S.G., Yoon, H. and Kim, S.Y. (2017) Aloesin from Aloe vera Accelerates Skin Wound Healing by Modulating MAPK/Rho and Smad Signaling Pathways in Vitro and in Vivo. Phytomedicine, 28, 19-26. https://doi.org/10.1016/j.phymed.2017.02.005

[27] Yamao, M., Naoki, H., Kunida, K., Aoki, K., Matsuda, M. and Ishii, S. (2015) Distinct Predictive Performance of Rac1 and Cdc42 in Cell Migration. Scientific Reports, 5, Article No. 17527. https://doi.org/10.1038/srep17527

[28] Philips, T., Ongenae, K., Kanj, L. and Slaterfreedberg, J. (1995) A Randomized Study of an Aloe vera Derivative Gel Dressing versus Conventional Treatment after Shave Biopsy Excisions. Wounds, 7, 200-202.

[29] Zhang, L. and Tizard, I.R. (1996) Activation of a Mouse Macrophage Cell Line by 
Acemannan: The Major Carbohydrate Fraction from Aloe vera Gel. Immunopharmacology, 35, 119-128. https://doi.org/10.1016/S0162-3109(96)00135-X

[30] Akgun, S.G., Aydemir, S., Ozkan, N., Yuksel, M. and Sardas, S. (2017) Evaluation of the Wound Healing Potential of Aloe vera-Based Extract of Nerium oleander. Northern Clinics of Istanbul, 4, 205-212.

[31] Duansak, D., Somboonwong, J. and Patumraj, S. (2003) Effects of Aloe vera on Leukocyte Adhesion and TNF-alpha and IL-6 Levels in Burn Wounded Rats. Clinical Hemorheology and Microcirculation, 29, 239-246.

[32] Akhoondinasab, M.R., Akhoondinasab, M. and Saberi, M. (2014) Comparison of Healing Effect of Aloe vera Extract and Silver Sulfadiazine in Burn Injuries in Experimental Rat Model. World Journal of Plastic Surgery, 3, 29-34.

[33] Heggers, J.P., Kucukcelibi, A., Stabenau, C.J., et al. (1995) Wound Healing Effects of Aloe Gel and Other Topical Antibacterial Agents on Rat Skin. Phytotherapy Research, 9, 455-457. https://doi.org/10.1002/ptr.2650090615

[34] Kemegne, G.A., Mkounga, P., Essia Ngang, J.J., Sado Kamdem, S.L. and Nkengfack, A.E. (2017) Antimicrobial Structure Activity Relationship of Five Anthraquinones of Emodine Type Isolated from Vismia laurentii. BMC Microbiology, 17, 41. https://doi.org/10.1186/s12866-017-0954-1

[35] Robson, M.C., Heggers, J.P. and Hagstrom, W.J. (1982) Myth, Magic, Witchcraft, or Fact? Aloe vera Revisited. Journal of Burn Care \& Rehabilitation, 3, 157-163. https://doi.org/10.1097/00004630-198205000-00005

[36] Parihar, A., Parihar, M.S., Milner, S. and Bhat, S. (2008) Oxidative Stress and Anti-Oxidative Mobilization in Burn Injury. Burns, 34, 6-17.

https://doi.org/10.1016/j.burns.2007.04.009

[37] Steinbeck, M.J., Khan, A.U. and Karnovsky, M.J. (1993) Extracellular Production of Singlet Oxygen by Stimulated Macrophages Quantified Using 9,10-Diphenylanthracene and Perylene in a Polystyrene Film. Journal of Biological Chemistry, 268, 15649-15654.

[38] Gurbuz, V., Corak, A., Yegen, B.C., Kurtel, H. and Alican, I. (1997) Oxidative Organ Damage in a Rat Model of Thermal Injury: The Effect of Cyclosporin A. Burns, 23, 37-42. https://doi.org/10.1016/S0305-4179(96)00072-1

[39] Saitoh, D., Okada, Y., Ookawara, T., et al. (1994) Prevention of Ongoing Lipid Peroxidation by Wound Excision and Superoxide Dismutase Treatment in the Burned Rat. The American Journal of Emergency Medicine, 12, 142-146. https://doi.org/10.1016/0735-6757(94)90233-X

[40] Shi, Y. and Massague, J. (2003) Mechanisms of TGF-beta Signaling from Cell Membrane to the Nucleus. Cell, 113, 685-700.

https://doi.org/10.1016/S0092-8674(03)00432-X

[41] Sanchez-Elsner, T., Botella, L.M., Velasco, B., Corbi, A., Attisano, L. and Bernabeu, C. (2001) Synergistic Cooperation between Hypoxia and Transforming Growth Factor-Beta Pathways on Human Vascular Endothelial Growth Factor Gene Expression. Journal of Biological Chemistry, 276, 38527-38535. https://doi.org/10.1074/jbc.M104536200

[42] Kane, C.J., Hebda, P.A., Mansbridge, J.N. and Hanawalt, P.C. (1991) Direct Evidence for Spatial and Temporal Regulation of Transforming Growth Factor Beta 1 Expression during Cutaneous Wound Healing. Journal of Cellular Physiology, 148, 157-173. https://doi.org/10.1002/jcp.1041480119

[43] Lin, S., Xie, J., Gong, T., et al. (2016) Smad Signal Pathway Regulates Angiogenesis via Endothelial Cell in an Adipose-Derived Stromal Cell/Endothelial Cell Co-Culture, 
3D Gel Model. Molecular and Cellular Biochemistry, 412, 281-288.

https://doi.org/10.1007/s11010-015-2634-5

[44] Muthusamy, V. and Piva, T.J. (2010) The UV Response of the Skin: A Review of the MAPK, NFkappaB and TNFalpha Signal Transduction Pathways. Archives of Dermatological Research, 302, 5-17. https://doi.org/10.1007/s00403-009-0994-y

[45] Moon, E.J., Lee, Y.M., Lee, O.H., et al. (1999) A Novel Angiogenic Factor Derived from Aloe vera Gel: Beta-Sitosterol, a Plant Sterol. Angiogenesis, 3, 117-123. https://doi.org/10.1023/A:1009058232389

[46] Choi, S., Kim, K.W., Choi, J.S., et al. (2002) Angiogenic Activity of Beta-Sitosterol in the Ischaemia/Reperfusion-Damaged Brain of Mongolian gerbil. Planta Medica, 68, 330-335. https://doi.org/10.1055/s-2002-26750

[47] Lee, M.J., Lee, O.H., Yoon, S.H., et al. (1998) In Vitro Angiogenic Activity of Aloe vera Gel on Calf Pulmonary Artery Endothelial (CPAE) Cells. Archives of Pharmacal Research, 21, 260-265. https://doi.org/10.1007/BF02975285

[48] Majewska, I. and Gendaszewska-Darmach, E. (2011) Proangiogenic Activity of Plant Extracts in Accelerating Wound Healing-A New Face of Old Phytomedicines. Acta Biochimica Polonica, 58, 449-460.

https://doi.org/10.18388/abp.2011_2210

[49] Hormozi, M., Assaei, R. and Boroujeni, M.B. (2017) The Effect of Aloe vera on the Expression of Wound Healing Factors (TGFbetal and bFGF) in Mouse Embryonic Fibroblast Cell: In Vitro Study. Biomedicine \& Pharmacotherapy, 88, 610-616. https://doi.org/10.1016/j.biopha.2017.01.095

[50] Abreu-Blanco, M.T., Verboon, J.M. and Parkhurst, S.M. (2014) Coordination of Rho Family GTPase Activities to Orchestrate Cytoskeleton Responses during Cell Wound Repair. Current Biology, 24, 144-155. https://doi.org/10.1016/j.cub.2013.11.048

[51] Duncan, M.R., Frazier, K.S., Abramson, S., et al. (1999) Connective Tissue Growth Factor Mediates Transforming Growth Factor Beta-Induced Collagen Synthesis: Down-Regulation by cAMP. The FASEB Journal, 13, 1774-1786. https://doi.org/10.1096/fasebj.13.13.1774

[52] Maenthaisong, R., Chaiyakunapruk, N., Niruntraporn, S. and Kongkaew, C. (2007) The Efficacy of Aloe vera Used for Burn Wound Healing: A Systematic Review. Burns, 33, 713-718. https://doi.org/10.1016/j.burns.2006.10.384

[53] Oryan, A., Mohammadalipour, A., Moshiri, A. and Tabandeh, M.R. (2016) Topical Application of Aloe vera Accelerated Wound Healing, Modeling, and Remodeling: An Experimental Study. Annals of Plastic Surgery, 77, 37-46. https://doi.org/10.1097/SAP.0000000000000239

[54] Barkat, M.A., Harshita, Ahmad, I., et al. (2017) Nanosuspension-Based Aloe vera Gel of Silver Sulfadiazine with Improved Wound Healing Activity. AAPS PharmSciTech, 18, 3274-3285. https://doi.org/10.1208/s12249-017-0817-y

[55] Coelho, F.H., Salvadori, G., Rados, P.V., et al. (2015) Topical Aloe vera (Aloe barbadensis Miller) Extract Does Not Accelerate the Oral Wound Healing in Rats. Phytotherapy Research, 29, 1102-1105. https://doi.org/10.1002/ptr.5352

[56] Topman, G., Lin, F.H. and Gefen, A. (2013) The Natural Medications for Wound Healing-Curcumin, Aloe-Vera and Ginger-Do Not Induce a Significant Effect on the Migration Kinematics of Cultured Fibroblasts. Journal of Biomechanics, 46, 170-174. https://doi.org/10.1016/j.jbiomech.2012.09.015

[57] Cuttle, L., Kempf, M., Kravchuk, O., et al. (2008) The Efficacy of Aloe vera, Tea Tree Oil and Saliva as First Aid Treatment for Partial Thickness Burn Injuries. 
Burns, 34, 1176-1182. https://doi.org/10.1016/j.burns.2008.03.012

[58] Davis, R.H., Rosenthal, K.Y., Cesario, L.R. and Rouw, G.A. (1989) Processed Aloe vera Administered Topically Inhibits Inflammation. Journal of the American Podiatric Medical Association, 79, 395-397.

https://doi.org/10.7547/87507315-79-8-395

[59] Heggers, J.P., Pineless, G.R. and Robson, M.C. (1979) Dermaide Aloe/ Aloe vera Gel: Comparison of the Antimicrobial Effects. The American Journal of Medical Technology, 41, 293-294.

[60] Yaron, A. (1993) Characterization of Aloe vera Gel before and after Autodegradation, and Stabilization of the Natural Fresh Gel. Phytotherapy Research, 7, S11-S13. https://doi.org/10.1002/ptr.2650070706

[61] Vogler, B.K. and Ernst, E. (1999) Aloe vera: A Systematic Review of Its Clinical Effectiveness. British Journal of General Practice, 49, 823-828.

[62] Heggers, J.P., Robson, M.C., Manavalen, K., et al. (1987) Experimental and Clinical Observations on Frostbite. Annals of Emergency Medicine, 16, 1056-1062.

https://doi.org/10.1016/S0196-0644(87)80758-8

[63] Miller, M.B. and Koltai, P.J. (1995) Treatment of Experimental Frostbite with Pentoxifylline and Aloe vera Cream. Archives of Otolaryngology-Head and Neck Surgery, 121, 678-680. https://doi.org/10.1001/archotol.1995.01890060076015

[64] Corn, C.C., Malone, J.M., Wachtel, T.L., et al. (1991) The Protection against and Treatment of a Liquid Propane Freeze Injury: An Experimental Model. Journal of Burn Care \& Rehabilitation, 12, 516-520. https://doi.org/10.1097/00004630-199111000-00005

[65] Burusapat, C., Supawan, M., Pruksapong, C., Pitiseree, A. and Suwantemee, C. (2018) Topical Aloe vera Gel for Accelerated Wound Healing of Split-Thickness Skin Graft Donor Sites: A Double-Blind, Randomized, Controlled Trial and Systematic Review. Plastic and Reconstructive Surgery, 142, 217-226.

https://doi.org/10.1097/PRS.0000000000004515

[66] Rao, S., Hegde, S.K., Baliga-Rao, M.P., Palatty, P.L., George, T. and Baliga, M.S. (2017) An Aloe vera-Based Cosmeceutical Cream Delays and Mitigates Ionizing Radiation-Induced Dermatitis in Head and Neck Cancer Patients Undergoing Curative Radiotherapy: A Clinical Study. Medicines (Basel), 4, 44. https://doi.org/10.3390/medicines4030044

[67] Williams, M.S., Burk, M., Loprinzi, C.L., et al. (1996) Phase III Double-Blind Evaluation of an Aloe vera Gel as a Prophylactic Agent for Radiation-Induced Skin Toxicity. International Journal of Radiation Oncology, Biology, Physics, 36, 345-349. https://doi.org/10.1016/S0360-3016(96)00320-3

[68] Ferreira, E.B., Vasques, C.I., Gadia, R., et al. (2017) Topical Interventions to Prevent Acute Radiation Dermatitis in Head and Neck Cancer Patients: A Systematic Review. Support Care Cancer, 25, 1001-1011.

https://doi.org/10.1007/s00520-016-3521-7

[69] Atiba, A., Nishimura, M., Kakinuma, S., et al. (2011) Aloe vera Oral Administration Accelerates Acute Radiation-Delayed Wound Healing by Stimulating Transforming Growth Factor-Beta and Fibroblast Growth Factor Production. The American Journal of Surgery, 201, 809-818. https://doi.org/10.1016/j.amjsurg.2010.06.017

[70] Somboonwong, J., Thanamittramanee, S., Jariyapongskul, A. and Patumraj, S. (2000) Therapeutic Effects of Aloe vera on Cutaneous Microcirculation and Wound Healing in Second Degree Burn Model in Rats. Journal of the Medical Association of Thailand, 83, 417-425. 
[71] Hjortdal, V.E., Sinclair, T., Kerrigan, C.L. and Solymoss, S. (1994) Arterial Ischemia in Skin Flaps: Microcirculatory Intravascular Thrombosis. Plastic and Reconstructive Surgery, 93, 375-385. https://doi.org/10.1097/00006534-199402000-00024

[72] Aral, M., Tuncer, S., Sencan, A., Elmas, C. and Ayhan, S. (2015) The Effect of Thrombolytic, Anticoagulant, and Vasodilator Agents on the Survival of Random Pattern Skin Flap. Journal of Reconstructive Microsurgery, 31, 487-492. https://doi.org/10.1055/s-0035-1554938

[73] Angel, M.F., Ramasastry, S.S., Swartz, W.M., et al. (1988) The Critical Relationship between Free Radicals and Degrees of Ischemia: Evidence for Tissue Intolerance of Marginal Perfusion. Plastic and Reconstructive Surgery, 81, 233-239. https://doi.org/10.1097/00006534-198802000-00017

[74] Das, S. and Maiti, A. (2013) Acrocyanosis: An Overview. Indian Journal of Dermatology, 58, 417-420. https://doi.org/10.4103/0019-5154.119946

[75] Sunderkotter, C. and Riemekasten, G. (2006) Pathophysiology and Clinical Consequences of Raynaud's Phenomenon Related to Systemic Sclerosis. Rheumatology (Oxford), 45, iii33-iii35. https://doi.org/10.1093/rheumatology/kel280

[76] Jimenez, S., Cervera, R., Font, J. and Ingelmo, M. (2003) The Epidemiology of Systemic Lupus Erythematosus. Clinical Reviews in Allergy \& Immunology, 25, 3-12. https://doi.org/10.1385/CRIAI:25:1:3

[77] Renaudineau, Y., Revelen, R., Levy, Y., et al. (1999) Anti-Endothelial Cell Antibodies in Systemic Sclerosis. Clinical and Diagnostic Laboratory Immunology, 6, 156-160. https://doi.org/10.1128/CDLI.6.2.156-160.1999

[78] Negi, V.S., Tripathy, N.K., Misra, R. and Nityanand, S. (1998) Antiendothelial Cell Antibodies in Scleroderma Correlate with Severe Digital Ischemia and Pulmonary Arterial Hypertension. The Journal of Rheumatology, 25, 462-466. https://pubmed.ncbi.nlm.nih.gov/9517764/

[79] Denton, C.P., Bickerstaff, M.C., Shiwen, X., et al. (1995) Serial Circulating Adhesion Molecule Levels Reflect Disease Severity in Systemic Sclerosis. British Journal of Rheumatology, 34, 1048-1054. https://doi.org/10.1093/rheumatology/34.11.1048

[80] Bruckdorfer, K.R., Hillary, J.B., Bunce, T., Vancheeswaran, R. and Black, C.M. (1995) Increased Susceptibility to Oxidation of Low-Density Lipoproteins Isolated from Patients with Systemic Sclerosis. Arthritis \& Rheumatology, 38, 1060-1067. https://doi.org/10.1002/art.1780380807

[81] Ames, P.R., Lupoli, S., Alves, J., et al. (1997) The Coagulation/Fibrinolysis Balance in Systemic Sclerosis: Evidence for a Haematological Stress Syndrome. British Journal of Rheumatology, 36, 1045-1050. https://doi.org/10.1093/rheumatology/36.10.1045

[82] Hughes, M., Moore, T., Manning, J., et al. (2017) Reduced Perfusion in Systemic Sclerosis Digital Ulcers (Both Fingertip and Extensor) Can Be Increased by Topical Application of Glyceryl Trinitrate. Microvascular Research, 111, 32-36.

https://doi.org/10.1016/j.mvr.2016.12.008

[83] Rahmani, N., Khademloo, M., Vosoughi, K. and Assadpour, S. (2014) Effects of Aloe vera Cream on Chronic Anal Fissure Pain, Wound Healing and Hemorrhaging upon Defection: A Prospective Double Blind Clinical Trial. European Review for Medical and Pharmacological Sciences, 18, 1078-1084.

[84] Heggers, J.P., Elzaim, H., Garfield, R., et al. (1997) Effect of the Combination of Aloe vera, Nitroglycerin, and L-NAME on Wound Healing in the Rat Excisional Model. The Journal of Alternative and Complementary Medicine, 3, 149-153. https://doi.org/10.1089/acm.1997.3.149 